\title{
Erratum to: Recent Progresses of Iridium Complex-Containing Macromolecules for Solution-Processed Organic Light-Emitting Diodes
}

\author{
Aihui Liang $\cdot$ Lei Ying $\cdot$ Fei Huang
}

Published online: 30 December 2014

(C) Springer Science+Business Media New York 2014

Erratum to: J Inorg Organomet Polym (2014)

24:905-926

DOI 10.1007/s10904-014-0099-8

A footnote was missing in the original version of this review article. It should contain the following footnote: This paper is dedicated to Professor Ben Zhong Tang in honor of his substantial research accomplishments.

The online version of the original article can be found under doi:10.1007/s10904-014-0099-8.

\footnotetext{
A. Liang $(\bowtie)$

College of Chemistry and Chemical Engineering,

Jiangxi Normal University, Nanchang 330022,

People's Republic of China

e-mail: lah14god@163.com

L. Ying $\cdot$ F. Huang $(\bowtie)$

State Key Laboratory of Luminescent Materials and Devices, Institute of Polymer Optoelectronic Materials and Devices,

South China University of Technology, Guangzhou 510640,

People's Republic of China

e-mail: msfhuang@scut.edu.cn
} 